\title{
The Great Plains Interactive Distance Education Alliance
}

\author{
Virginia M. Moxley and Sue C. Maes \\ Kansas State University
}

THE LANDSCAPE FOR HIGHER EDUCATION DELIVERY has evolved from the traditional classroom-based, instructor-led format toward one that is internetbased and learner-led. To manage a change of this magnitude in an era of fragile public funding, universities-and higher education oversight boards and state legislatures-have discovered the potential of inter-institutional collaboration to deploy rapidly new undergraduate and postbaccalaureate programs to meet emerging needs of the professions and to target professionals seeking education for career advancement and career change. Institutions are banding together in innovative ways to capitalize on their collective and interconnected technological and human capacity, and many states have formed statewide alliances for the purpose of delivering educational courses and programs to students at a distance.

The Great Plains Interactive Distance Education Alliance for the Human Sciences (Great Plains IDEA) that is described in this paper is a consortium of ten human sciences colleges located in ten states that capitalizes on the talents of interinstitutional faculty teams to offer distance education master's degrees and postbaccalaureate certificates. Institutional members of the Great Plains IDEA are Colorado State University, lowa State University, Kansas State University, Michigan State University, Montana State University, University of Nebraska, North Dakota State University, Oklahoma State University, South Dakota State University, and Texas Tech University.

The Great Plains IDEA was created by academic deans to serve a particular academic discipline within the partner universities. Such an alliance depends on the goodwill of the institutional representatives and the shared need for the programs rather than on a reallocation of institutional resources into alliance operations. While such alliances cannot be developed and sustained without support by the chief academic officers, they are initiated and led by disciplinary academic administrators. A program alliance is quite different from an institutional alliance. Among the differences are the following:

The alliance is organized to meet a disciplinary need for a program that no one institution can meet because of lack of human capacity to implement a new distance education program. 
- $\quad$ Administrators have direct oversight of the faculty who participate in interinstitutional programs; they manage workload assignments and perform assessments of the faculty from their institutions.

. Inter-institutional faculty teams propose and develop programs. Faculty who comprise these teams also teach courses and advise students enrolled in the programs.

Alliance administration is minimal. There is no need to fund much infrastructure or staff-work is distributed among participants with little central management.

\section{HISTORY}

The Great Plains Interactive Distance Education Alliance was founded in 1994 with the modest goal of increasing the access of rural professionals to postbaccalaureate educational opportunities by creating a marketplace for sharing distance education graduate courses. The University of Nebraska College of Human Resources and Consumer Sciences had initiated a distance education master's degree and called a meeting of academic deans from peer institutions to discuss possibilities for collaboration. The alliance, which had an initial membership of eight institutions, is now an alliance of ten institutions from ten states, six of which took part in the initial meeting. The alliance evolution occurred in several overlapping phases. Though the first meeting was intended to identify collaborators in distance education, both collaborative and competitive tendencies emerged. Although it was unclear then what the future of distance education might mean for graduate education, no institution wanted to be left behind. The coming together raised the bar for distance education programming and created a form of peer pressure that advanced the engagement in distance education of all participating universities.

As the administrative team met, the benchmarks for distance program delivery and needs became clearer. In many ways this created frustration because we knew more and more about the public need, but we also knew that we did not have the resources and faculty with distance teaching skills. During this phase, the administrative team shared information and engaged in "show and tell" about their institutional distance education offerings, and the alliance sponsored faculty development workshops to prepare faculty to teach online.

\section{PHASE I: LAYING THE FOUNDATION 1994-98}

The development of trust is essential to building alliances. The first step in building trust is to select with care the partners with whom you will work-if the people are not trustworthy, the practices will not be trusted. If the partner institutions are not invested in the success of the venture, the progress and sustainability of the alliance will be compromised. The second step is listening to and learning from each other. With a foundation of trust and an atmosphere of open communication, we were able to begin working on policies. Linda Hoover, Dean of the College of Human Sciences at Texas Tech University, characterizes the process in this way: "As we've worked through trying to develop policies and procedures for the alliance, 
we found that from university to university, everyone is pretty flexible until you get to their 'sacred' policy or procedures. But if a real alliance is going to be created, you have to trust each other, you have to be very flexible, you have to move toward truly realizing that flexibility, and putting away some of those sacred policies and procedures" (Hoover, video clip).

When the alliance began in the mid-'90s, graduate faculty were not particularly interested in teaching via the Internet; in truth, there were many disincentives for them to teach at a distance: the number of students with whom they worked would increase, they would have to learn new teaching methodologies, and their relationships with colleagues might be negatively affected. For this reason, during the first two years, the focus was on educating the faculty and administrative participants. This was done through two satellite conferences and two face-to-face conferences that focused on the increasing significance of distance education, the changing public perception of higher education, and the technological advances that were allowing us to extend the reach of our educational programs over the Internet. The US Department of Agriculture awarded two Agricultural Telecommunication grants to the University of Nebraska to support these conferences.

By 1996, Internet access to rural and remote locations in our states had expanded, rural professionals increasingly demanded education that they could access from their homes and workplaces, courseware to support Internet delivery of distance education courses was commercialized, and faculty and administrators were growing interested in meeting the opportunities created by this convergence. The University of Nebraska created intensive, week-long Faculty Development LearnShops to help faculty adapt courses to web-based instruction. Each institution sent five faculty members to workshops where they had hands-on experience with instructional software.

Two years after the first meeting of the alliance, we were sharing courses and a web page was implemented (http://www.gpidea.org). At this point, the realities of institutional policies that limited our ability to capitalize on each others' courses came to the forefront of our attention. For over a year we debated which instructional software would best support the inter-institutional course, finally determining that faculty should use the software that their employing institution supported. In retrospect, this decision seems obvious, but at the time it was anything but. Additionally, because each institution placed restrictions on who was eligible to teach graduate courses, we needed a plan to establish the qualifications of those assigned to teach shared courses. A team of faculty members acting as the credentials committee provided an elegant answer to the dilemma: if an individual is qualified to teach graduate courses at the employing institution, the individual should be considered qualified to teach courses for students at all institutions, a decision that continues to serve the alliance well. 


\section{PHASE II: PROGRAM DEVELOPMENT 1998-2000}

As the alliance evolved into a functioning entity, the focus remained on meeting needs of professional audiences. However, the alliance found that those needs called for programs, not just courses. Faculty participants in alliancesponsored workshops began to function much as institutional colleagues dosharing ideas, strategies, collaborating on teaching and research. This collegiality led a faculty member to suggest that we offer a master's degree in financial planning, a degree that no institution had the capacity to offer alone and one for which the need was apparent. Graduate faculty members from seven universities collaborated to develop the curricula, assign teaching responsibilities, and set qualifications for admission to the program. Although this process required only four days of face-to-face contact, the time elapsed from the first meeting to the program implementation was two years. Now in its third year, the program enrolls more than 100 students and is fully operational.

\section{PHASE III: BUILDING A POLICY AND PRACTICE FRAMEWORK 2000 AND BEYOND}

When the first inter-institutional program was implemented, the need for binding agreements became urgent. We began to develop bylaws for the alliance, memoranda of agreements for the programs, financial agreements about pricing courses and transferring funds, secure student data management processes to enable one institution to provide instruction and another to provide transcripts, processes for developing and assessing programs, and written principles to define how the alliance functioned. This work, supported by a grant from the US Department of Education Fund for the Improvement of Postsecondary Education Learning Anywhere Anytime Partnership Project, led to significant advances in alliance operations and outcomes and has enabled us to create model policies and practices that can be used by others.

\section{CULTURE}

Moving from campus-based, limited-enrollment graduate education to Internet-based education with larger enrollments per program is a major transition, particularly in research universities. Our alliance did not set out to affect fundamental change in the member universities, but as an outcome of our work, our institutions as well as our alliance have matured.

From the outset, the culture of the Great Plains IDEA has been one where administrative leadership is shared, policies are designed to facilitate academic innovation, faculty participants provide academic leadership, and both alliance and institutional interests govern decisions. The notion of shared governance is so pervasive in this alliance that formal memoranda of agreement about program and alliance participation were initiated only after effective working agreements were informally arranged and tested. In this alliance, agreement on principles precedes agreement on policies. 
The work of Rosabeth Moss Kanter (1994) that characterized the strategic advantages of business alliances guided the formation of our alliance. Kanter identified three fundamental aspects of business alliances that apply to higher education alliances:

1) Successful alliances yield benefits for the partners and evolve progressively in their possibilities.

2) Successful alliances involve collaboration (creating new value together) rather than mere exchange (getting something back for what you put in).

3) Successful alliances are supported by a dense web of interpersonal connections and internal infrastructures that enhance learning; they cannot be controlled by formal systems.

Alliance building is an intellectually and emotionally intense endeavor of great complexity. Each partner is required to give a little with the hope of getting a lot. However, because of the nature of academic institutions, when academic deans form alliances, they make work for other functional areas of the institutions they represent. For instance, although deans can provide the administrative and financial support to the faculty who develop and teach inter-institutional programs, they cannot price the programs without getting buy-in from the financial officer of the university. They cannot "transcript" the course grades without buy-in from the registrar. They cannot apply graduate courses taught by noninstitutional faculty to graduate programs of study without buy-in from graduate faculty leaders and administrators.

Inter-institutional teams of graduate faculty, graduate deans, chief financial officers, registrars, and academic deans conducted discussions and planning sessions that developed the policies and practices that define the Great Plains IDEA. This work is not simple. The teams, coming from functional areas, see issues differently. Within teams, members are wont to change their mindsgenerally for good reasons. For that reason, debate, reconsideration, and edits to documents are encouraged. The typical meeting of inter-institutional teams goes something like this: day one-everyone engages in working together on the assigned tasks; overnight-individually the participants dream, reflect, discuss, and think about the work of the first day; day two begins with challenges to the work from day one. This will look and feel like mutiny, but it is actually a necessary step toward realizing the synergy of working as a group.

Alliances have cultures and contexts-both require attention. The context for our alliance is that we focus on meeting needs collectively that could not be met by individual institutions. Furthermore, we focus on developing courses and programs that meet our collective academic standards. So when it comes to program approvals and reviews, we ask questions such as these about the context: Is what we deliver meeting the critical needs? Is what we offer measuring up academically? Is the alliance fitting our institution's goals? 


\section{PRINCIPLES}

To help us answer these questions and guide our work, we rely on deceptively simple principles:

Behave as equals: Explicitly stating this assumption has been essential to developing working relationships. Once this principle was accepted, other agreements became easy to adopt. Graduate faculty status at one institution is honored at all. Alliance courses taught by any institution are "transcripted" by every institution for their students in the course. The alliance website is institution-neutral in format, although it is housed at the lead institution.

Share leadership: Partner universities are represented as voting members of the alliance board, whose officers are elected from the membership and whose responsibilities rotate. All board members contribute to the leadership of alliance programs and projects. Our "leader-full" board, composed of academic administrators, is an important asset.

Respect and accommodate institutional differences: Although alliance curricula are the same everywhere, the course designations and program and degree titles are unique to each institution. Different approaches to faculty workload and compensation, technical, administrative, and financial arrangements, and institutional culture are accommodated.

Simplify student access: Students in alliance programs apply for admission to the institution from which they seek to receive their degree. Course advising and enrollment takes place at this institution. All courses are offered at a common price. Although courseware may differ, to the greatest extent possible, the differences in practice from one institution to another are transparent to students.

See the compelling elegance of simplicity (Carver, 1990): We value low input/high impact approaches to collaborative work. As Carver notes in his book, Boards That Make a Difference, "brevity is the unheralded secret of excellence" (page 43). When ten institutions, each employing a cadre of attorneys, engage in joint endeavors, there is a tendency to over-complicate the arrangements. Whenever possible, we move beyond the complexity inherent in the activity to find strategies to simplify working arrangements.

\section{THE GREAT PLAINS MODEL: POLICIES AND PRACTICES}

As a joint project of its ten institutional members, the Great Plains Interactive Distance Education Alliance for the Human Sciences is able to give students access to multi-institutional academic programs at the graduate level, including master's degrees and graduate certificates in family financial planning, gerontology, and youth development. The Great Plains IDEA also features single institution academic programs in family and consumer sciences (master's degree from the University of Nebraska), clothing and textiles (master's degree from the University of Nebraska), 
dietetics (bachelor's degree from Kansas State University), and restaurant, hotel, and institutional management (master's degree from Texas Tech University). The alliance, as such, does not offer courses and programs; it allows institutions to pool their instructional assets to create courses taught by faculty members from multiple institutions and attract students from multiple institutions. In effect, the members of the alliance purchase instruction from each other for the benefit of their students.

\section{Program and Curriculum Development}

Although human sciences academic deans are the prime movers of the Great Plains IDEA, they cannot "will" courses of programs to happen; inter-institutional faculty teams develop programs and curricula, which must be reviewed and approved by the institutions at which they are offered. The most successful interinstitutional undertakings are those that meet the following criteria:

- There is a large and growing professional demand for graduates.

- Individual institutions are unable to compile faculties sufficient to offer the programs.

. Courses are amendable to online delivery.

Once approved, the program name and course numbers for inter-institutional programs are unique to each member institution, and students enroll in courses or are admitted to a program of study through their home institution, which is responsible for assessing instructional quality and student learning outcomes.

The faculty teams function much like most departmental faculty colleagues: they meet occasionally, they communicate often, they argue, they philosophize, they behave erratically, they leave the university and must be replaced, but mostly, they behave as academicians who want to be part of a high-quality graduate program that attracts excellent students. There are rewards and costs for faculty who participate in inter-institutional programs. The prime rewards are the rich peer interaction with faculty from other institutions, opportunities to teach specializations that could not otherwise be offered by their institution, and the experience of teaching a much more diverse student group; participating faculty are also granted de facto teaching credentials at other member institutions.

The perceived (and often real) costs are an increase in workload responsibilities and the possibility of not having the support of departmental colleagues who are not involved in such programs. To encourage faculty participation, administrators provide financial, technical, and staff support for faculty and use a personnel assessment system that values contributions to interinstitutional programs. The commitment to faculty is further emphasized by the guiding principle that instructional software to support course delivery should be whatever is easiest for the teaching faculty, not the student, since faculty interaction with instructional software is more complex than student interaction (each institution provides a support desk for students enrolled in their courses). 


\section{Operational Policies}

Experts representing registrars, financial offices, continuing education, and graduate schools at member institutions recommend operational policies and procedures. A designated lead institution manages essential alliance functions (financial and data transaction oversight; alliance website maintenance; communications, governance, and program management support). The alliance holds no property and does not collect annual membership fees; financial support comes from student enrollments in courses and programs, in-kind contributions from partner institutions, and grants. According to Thomas Gibson, Treasurer of Montana State University, the rationale is quite clear: "First, we have a stake in the alliance only for those programs that we're directly participating in. Second, each participating institution pays the fee for each student that [it has] registered rather than paying a flat membership fee. So the cost is proportional to the level of participation by each institution. Third, only the students taking the alliance course are paying the fees, so that we can tell our administration and our Board of Regents that we're not paying new dues unless our students are directly benefiting from the process. Finally, we don't have to approach our institutions about coughing up new funds to pay for membership fees, ... a key factor in increasingly tight fiscal times" (Gibson, video clip).

The institutions in our alliance have very different tuition / fee structures, each subject to the rules and regulations of their institution and state higher education governing bodies. However, the costs of delivering courses for alliance programs were relatively level from institution to institution. Some institutions had a financial advantage because of their institution's pricing structure and others were financially disadvantaged. After a study of the marketplace practices in distance education, the state mandates for tuition and fees, and the costs of program delivery, the chief financial officers of the ten member institutions formulated a scheme for distributing income to support costs: 75 percent to the teaching institution, 12.5 percent to the enrolling institution for administration and advising, and 12.5 percent to the alliance. They also coined a new term to describe the fees for alliance courses, as Warren Madden, Vice President for Business and Finance at lowa State University, explains: "We found among all the different universities that tuition and fees mean different things at the different institutions and the different states. So we thought we'd come up with a new term that we could all accept, and we use the word 'common price'; that seems to be acceptable to everybody because it's no one institution's tuition and fee structure that's being used to develop this particular set of program costs" (Madden, video clip).

\section{LEADERSHIP AND COLLABORATION}

As previously noted, a board of college-level administrators who elect officers from among their members leads the alliance. Inter-institutional alliances, like academic departments within universities, require good leadership and a commitment to collaboration and innovation. We have been fortunate in having a succession of leaders who have shared a broad vision of the possibilities of the alliance, and who have engaged the interest of their peers as well as that of 
university employees in nonacademic roles who are essential partners. We have also formed a variety of teams-inter-institutional faculty cohorts for each program and institutional teams composed of individuals from all parts of campus that serve the Great Plains IDEA.

At the core of the alliance is a network of positive, supportive relationships that support alliance functions. The policies that are in place were not developed until relationships had evolved to the point where differences could be freely expressed, if not easily resolved. While the policies needed to meet the mandates of ten university attorneys operating under the laws of ten different states, they are only as solid as the relationships that led to their formulation; in a word, our trust is in people, not policies, and it is a testament to the founders of the alliance that the culture of collaboration that they encouraged has prevailed. There has been constant change over time both in terms of people and institutions, and although new participants need to get used to the principles and the culture of the Great Plains IDEA, they realize the value of the human relationships that drive the success of the alliance. In the words of Marjorie Kostelnik, Dean of the College of Education and Human Services, University of Nebraska-Lincoln, ... There is a cooperative spirit within the alliance. People sometimes think of that as being simply a group of people being nice to each other. This is more than nice. It is good business, because through this cooperative collective effort, we're... able to offer degrees that we couldn't offer otherwise. We're able to give the students who are enrolled in our programs access to students from all over the world and to faculty from all over the region, and as a result we are able to produce a higher quality product. So it isn't just a group of people being kind, although certainly that is part of it, but...in the end, it actually contributes to a better product...for the student, for the faculty, and for the institution" (Kostelnik, video clip).

For many reasons, it often seems hard for those of us in higher education to break the mold. There is a reason why this should be the case: we are quite good at doing what we do. But there are many reasons why this should not be the case: we are about the business of reinvention — of knowledge, of people, of cultures-and we should devote some of our attention to reinventing the enterprise of higher education. The Great Plains IDEA was conceived during a favorable climate for innovation, and given the current financial and competitive environment, it is recognized by university leaders as a model for the future. As Geoffrey Gamble, President of Montana State University puts it, "[The] Great Plains IDEA is fascinating because...embedded in it are two issues that are crucial to higher education today. Let me start with the distance learning part first. As you look across the nation, ... almost every year for the last decade...the largest and fastest growing segment of the population that wants higher education experience are people already in the workforce. The only way that they're going to get it is through a distance-learning model. And this model is perfect. It works very well. The other issue is the notion of partnerships. I'm convinced that the way of the future for all of higher education is to frame active partnerships with [the] private sector, ... with [the] public sector. And here we have a partnership that's rich. It spans ten institutions coming together to 
provide the very best education possible for students" (Gamble, video clip).

Required Statement for US Department of Education: The contents of this paper were developed under a grant from the US Department of Education. However, those contents do not necessarily represent the policy of the Department of Education, and the reader should not assume endorsement by the federal government.

\section{REFERENCES}

Carver, J. (1990). Boards that make a difference: A new design for leadership in nonprofit and public organizations. San Francisco: Jossey-Bass.

Gamble, G. (2003, March). Montana State University, Department of Communication Services. Video Clip.

Gibson, T. (2003, March). Montana State University, Department of Communication Services, Video clip.

Hoover, L. (2003, March). Texas Tech University, News and Publications. Video clip.

Kanter, R. M. (1994). "Collaborative advantage: the art of alliances." Harvard Business Review, 72(4), pages 96-108.

Kostelnik, M. (2003, March). University of Nebraska, Department of Communications and Information Technology. Video clip.

Madden, W. (2003, March). Iowa State University, Instructional Technology Center. Video clip.

Copyright 2003, Virginia M. Moxley, Virginia M. Moxley is Associate Dean, College of Human Ecology, Kansas State University, and Chair, Board of Directors, Great Plains Interactive Distance Education Alliance. Sue C. Maes is Senior Development Officer, Kansas State University, and former president of the University Continuing Education Association. 